\title{
ChemComm
}

\section{A novel flavin derivative reveals the impact of glucose on oxidative stress in adipocytes $\dagger$}

Cite this: Chem. Commun., 2014, 50,8181

Received 8th May 2014,

Accepted 5th June 2014

DOI: $10.1039 / \mathrm{c} 4 \mathrm{cc} 03464 \mathrm{c}$

www.rsc.org/chemcomm

We present the synthesis and characterisation of naphthalimide-flavin redox sensor 1 (NpFR1), a novel flavin molecule that is almost nonfluorescent in reduced form, but oxidation gives rise to a 125-fold increase in fluorescence. Confocal microscopy experiments confirm that NpFR1 is sensitive to redox changes within living cells.

Oxidative stress - a sustained elevation in the oxidative capacity of cell - arises from a build-up of oxidising cellular components, such as reactive oxygen species (ROS) and redox-active metals. ${ }^{1,2}$ It is a natural consequence of aging, but is also implicated in many diseases such as cardiovascular disease, ${ }^{3}$ arthritis, ${ }^{4}$ Alzheimer's disease, ${ }^{5}$ diabetes ${ }^{1,6}$ and obesity. ${ }^{7,8}$ Oxidative stress is commonly studied by monitoring the causes of increased oxidative capacity (such as levels of an individual ROS) or analysing the downstream effects (for example, expression of antioxidant genes). A much clearer picture will be gained, however, from the cell's oxidative capacity itself. This can be best achieved by measurement of the redox state of a cell, or sub-cellular compartment. To date, a limited number of fluorescent redox sensors have been developed, based on both fluorescent proteins ${ }^{9}$ and small organic molecules. ${ }^{10-12}$ The challenge in the design of such probes is in tuning the reduction potential of the probe such that its dynamic range is appropriate to measurement of cellular processes. We report here a novel fluorescent redox sensor, naphthalimide-flavin redox sensor 1 (NpFR1), and its application to the study of oxidative stress in adipocytes.

NpFR1 was designed based on the flavin moiety (Fig. 1), a group which plays important roles in sub-cellular redox processes, in the redox cofactors flavin adenine dehydrogenase (FAD) and flavin mononucleotide (FMN), and in the vitamin riboflavin. ${ }^{13}$ Flavin reductions are therefore well tuned to biologically-relevant potentials. In addition, flavins are typically fluorescent in oxidised form and non-fluorescent upon reduction. ${ }^{14}$ These properties

School of Chemistry, The University of Sydney, New South Wales, 2006, Australia. E-mail: elizabeth.new@sydney.edu.au

$\dagger$ Electronic supplementary information (ESI) available. See DOI: 10.1039/ c4cc03464c<smiles>[R3]c1cc2nc3c(=O)n([R1])c(=O)nc-3n([R2])c2cc1[R]</smiles>

Flavin<smiles>O=c1[nH]c(=O)c2nc3ccccc3c(=O)nc2[nH]1</smiles>

Isoalloxazine<smiles>O=c1[nH]c(=O)c2nc3ccccc3nc2[nH]1</smiles>

Alloxazine

Fig. 1 Generic structure of flavin, showing alloxazine and isoalloxazine forms.

make flavins ideal for incorporation into a fluorescent redox sensor. Since flavins are naturally found within cells, and contribute to cellular autofluorescence, ${ }^{15}$ we aimed to design a probe with fluorescence distinct from naturally-occurring flavins. This was achieved by incorporating a naphthalimide fluorophore into the final probe. The probe design also included a non-hydrogen atom at the $\mathrm{N}-10$ position of the flavin, as this is required to stabilise the isoalloxazine form over the alloxazine form, and to maintain reversibility of reduction. ${ }^{16}$

NpFR1 was synthesised by the alloxan monohydrate method first reported by Kuhn and Reinemund (Scheme 1). ${ }^{17}$ Alkylation of 4-bromo-1,8-naphthalic anhydride (1) gave 4-bromo- $N$-butyl-1,8naphthalimide (2), followed by nitration of 2 to afford 3-nitro-4bromo- $N$-butyl-1,8-naphthalimide (3). Alkylation with propylamine in acetonitrile gave the corresponding propylamino compound (4), which was reduced with stannous chloride to give a naphthalimide derivative bearing adjacent primary and secondary amines (5), a suitable substrate for the alloxan monohydrate reaction. $\mathbf{5}$ was reacted with alloxan monohydrate in the presence of boric acid to give NpFR1.

Photophysical characterisation of NpFR1 was performed in HEPES buffer (100 mM, pH 7.4). NpFR1 showed maximum absorption at 395 and $463 \mathrm{~nm}(\log \varepsilon=6.2$ and 4 respectively), 
<smiles>CCCCN1C(=O)c2cccc3c(Br)ccc(c23)C(=O)N1CCCC</smiles>

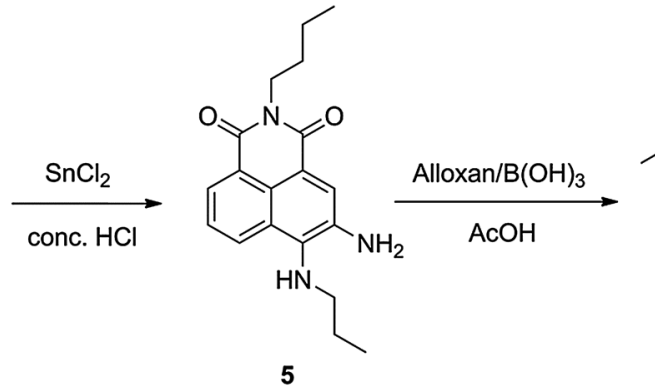<smiles>CCCCn1[nH]c(=O)c2cc3nc4c(=O)[nH]c(=O)nc4n(CCC)c3c3cccc(c1=O)c23</smiles>

Scheme 1 Synthesis of naphthalimide-flavin redox sensor 1 (NpFR1).

and maximum emission at $545 \mathrm{~nm}(\Phi=0.186)$. This represented a 27 and $14 \mathrm{~nm}$ red-shift in absorption and emission respectively compared to riboflavin (Fig. S1, ESI $\dagger$ ). While we had originally expected a larger shift in the fluorescence upon addition of the naphthalimide group, the new molecule fulfilled our aims of a distinct emission spectrum that could be resolved by spectral imaging confocal microscopy. Treatment of NpFR1 with various mild reductants, including sodium thiosulfate, sodium cyanoborohydride, dithiothreitol (DTT) and glutathione (GSH) gave the reduced form of the probe, which exhibited 110-fold lower absorbance and 125-fold lower emission (Fig. 2a). NpFR1 could be re-oxidised by air or by hydrogen peroxide, restoring its original fluorescence, and this oxidation-reduction cycle could be repeated multiple times without loss of response (Fig. 2b). Cyclic voltammetry confirms the reversibility of the process, with a reduction potential of $-336 \mathrm{mV} v$ s. SHE (Fig. S2, ESI $\dagger$ ). Interestingly, upon higher energy excitation $(380 \mathrm{~nm})$, an additional emission peak could be observed at $440 \mathrm{~nm}$ which was unaffected by reduction and oxidation, suggesting potential application as a ratiometric probe (Fig. S3, ESI $\dagger$ ). Re-oxidation occurred very rapidly, with $95 \%$ of the initial fluorescence regained after 4 minutes (Fig. S4, ESI $\dagger$ ). The magnitude of the fluorescence change upon reduction and the kinetics of re-oxidation for NpFR1 are very similar to those of riboflavin ${ }^{18}$ suggesting a similar sensing mechanism, involving fluorescence from the planar oxidised flavin and loss of the fluorescence in the non-planar, reduced form. Control experiments confirmed that the emissions of NpFR1 in oxidised and reduced form are constant over the $\mathrm{pH}$ range 2 to 9 (Fig. S5, ESI $\dagger$ ) and were unaffected by the presence of common metal ions (Fig. S6, ESI $\dagger$ ). Fluorescence intensity increases were observed for a range of diverse oxidants (Fig. S7, ESI $\dagger$ ), demonstrating the utility of NpFR1 as a probe of the general redox environment. Furthermore, the probe shows sensitivity for small changes in reduced:oxidised glutathione ratios in a biologically-relevant range (Fig. S8, ESI $\dagger$ ). ${ }^{19}$
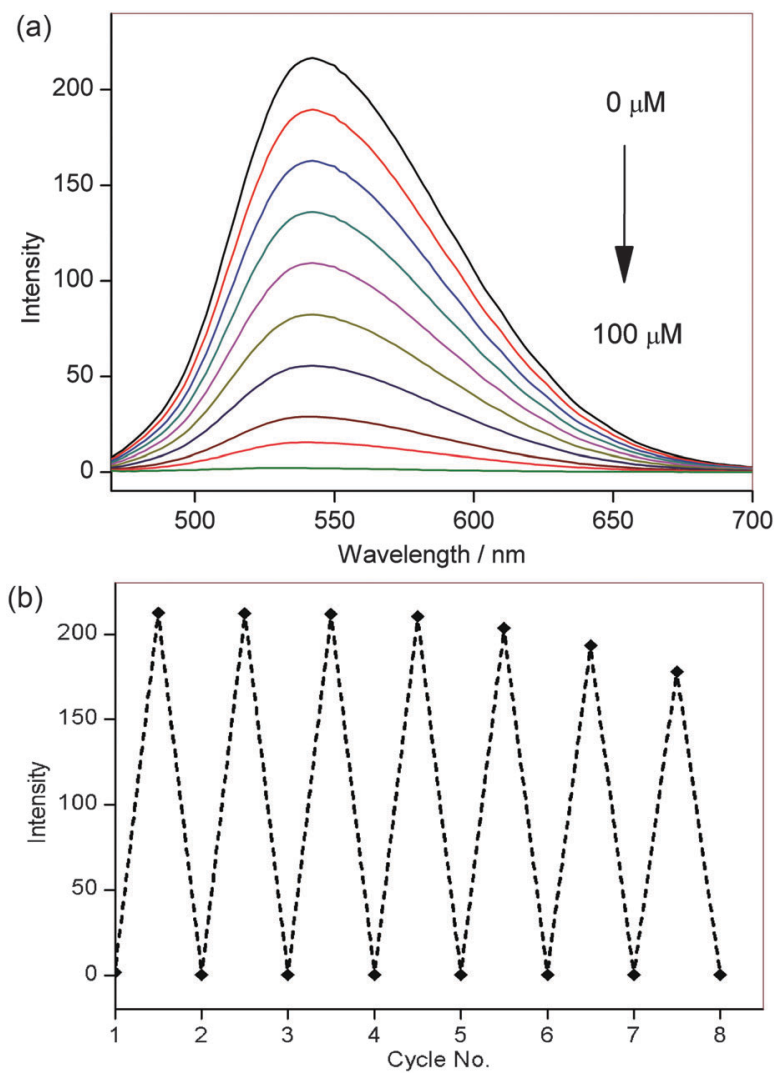

Fig. 2 Photophysical behaviour of NpFR1. (a) Fluorescence emission of NpFR1 ( $5 \mu \mathrm{M}, \lambda_{\text {ex }}=405 \mathrm{~nm}$ ) with the incremental addition of sodium dithionite. (b) Fluorescence response of NpFR1 to cycles of oxidation and reduction. Reduction was achieved with sodium dithionite $(100 \mu \mathrm{M})$ followed by re-oxidation with $250 \mu \mathrm{M}$ $\mathrm{H}_{2} \mathrm{O}_{2}$. Spectra were recorded $5 \mathrm{~min}$ after the addition of reducing and oxidising agents. All spectra were acquired in HEPES buffer (100 mM, pH 7.4).

Having demonstrated the redox sensitivity and reversibility of NpFR1, we next sought to test its ability to respond to changes in 
(a)

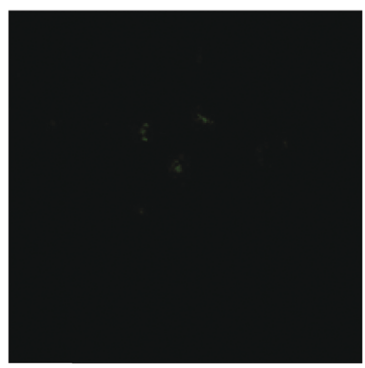

(c)

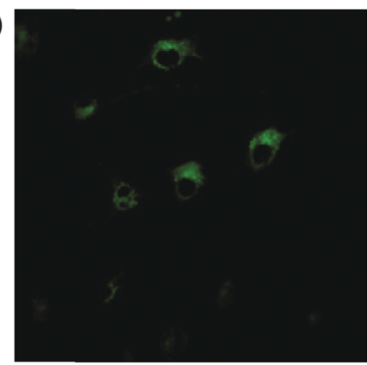

(e)

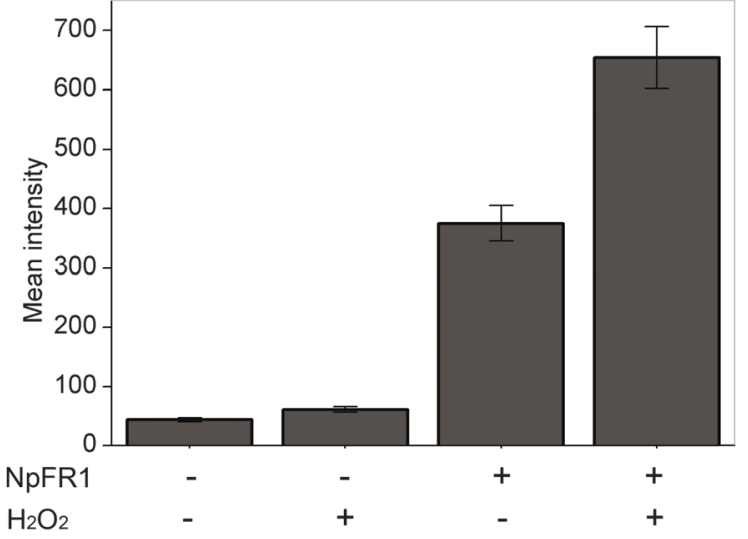

Fig. 3 Imaging of NpFR1 in 3T3-L1 preadipocytes treated with (a) vehicle control (b) $\mathrm{H}_{2} \mathrm{O}_{2}(100 \mu \mathrm{M}, 2$ min), (c) NpFR1 $(50 \mu \mathrm{M}, 2$ h) and (d) NpFR1 $(50 \mu \mathrm{M}, 2 \mathrm{~h})$ followed by $\mathrm{H}_{2} \mathrm{O}_{2}(100 \mu \mathrm{M}, 2 \mathrm{~min})$. Scale bar represents $50 \mu \mathrm{m}$ $\lambda_{\mathrm{ex}}=405 \mathrm{~nm}$. (e) Integrated emission from $510 \mathrm{~nm}$ to $610 \mathrm{~nm}$. Values are the mean ratio generated from the intensity from five fields of cells. Error bars represent standard error measurement (s.e.m.)

redox state in cultured cells. 3T3-L1 preadipocytes that had been incubated with $50 \mu \mathrm{M}$ NpFR1 showed noticeable fluorescence (Fig. 3c), whilst untreated, control cells exhibited negligible fluorescence (Fig. 3a). Cells which had been treated with $\mathrm{H}_{2} \mathrm{O}_{2}$ for 2 minutes after incubation with NpFR1 showed a significant fluorescence enhancement (Fig. 3d), consistent with oxidation of the cellular environment. Importantly, cells treated with $\mathrm{H}_{2} \mathrm{O}_{2}$ but no NpFR1 showed no fluorescence, confirming that any fluorescence observed in this experiment is due to the probe, and not to the oxidation of endogenous flavins. This provides important validation that there is no interference from intracellular flavins, in either oxidised or reduced form.

With these microscopy studies showing that NpFR1 is able to report on changes in oxidative capacity within cells, we aimed to use the probe to detect induced changes in redox state, and specifically to study the effect of glucose in adipocytes. For these studies, both 3T3-L1 preadipocytes and mature 3T3-L1 adipocytes were studied. By imaging cells as they differentiated into
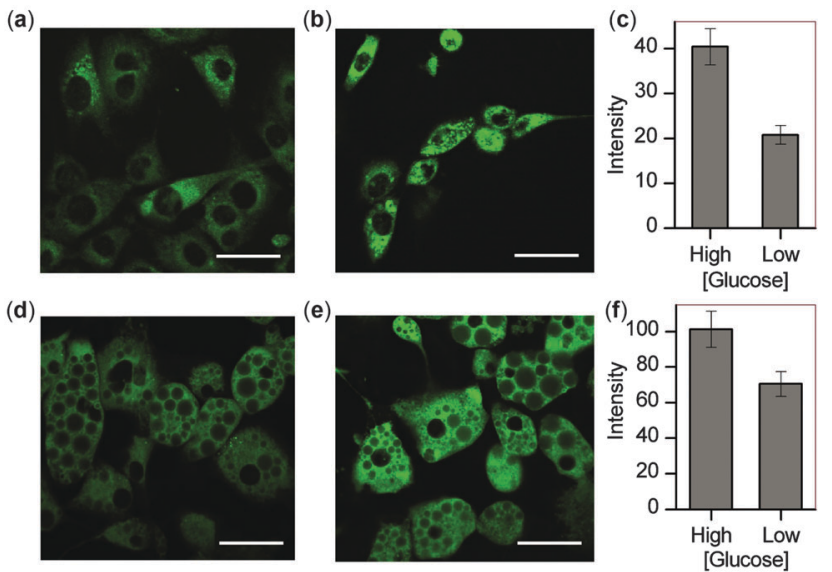

Fig. 4 Changes in oxidative capacity of 3T3-L1 pre-adipocytes and mature adipocytes incubated under different glucose conditions. (a), (b), (d), and (e) are confocal microscopy images of 3T3-L1 cells treated incubated with NpFR1 (50 $\mu$ M, 2 hours). (a) Pre-adipocytes cultured in low glucose $(10 \mu \mathrm{M}, 7 \mathrm{~d}),($ b) pre-adipocytes cultured in high glucose (25 $\mu \mathrm{M}, 7 \mathrm{~d})$, (d) mature adipocytes cultured in low glucose (10 $\mu \mathrm{M}, 7 \mathrm{~d})$, (e) mature adipocytes cultured in high glucose $(25 \mu \mathrm{M}, 7 \mathrm{~d})$. Scale bars represent $50 \mu \mathrm{m}$. Graphs show relative integrated emission from $510 \mathrm{~nm}$ to $610 \mathrm{~nm}$ from (c) 3T3-L1 preadipocytes and (f) mature adipocytes. Values are the mean ratio generated from the intensity from ten fields of cells. Error bars represent standard error measurement (s.e.m.).

mature adipocytes, we found that fluorescence intensity correlated with lipid accumulation, indicating that oxidative capacity increases as adipocytes mature (Fig. S9, ESI $\dagger$ ). We cultured preadipocytes and mature adipocytes in differing concentrations of glucose, and measured their oxidative capacity by microscopy using NpFR1. For both cell types, cells cultured in higher glucose concentrations exhibited higher fluorescence, indicative of an increased oxidative capacity (Fig. 4). These results are consistent with higher levels of metabolism under conditions of greater glucose consumption, which leads to greater superoxide formation due to increased electron leakage from the electron transport chain. They are also consistent with findings that obesity, in which cells experience constitutively higher levels of glucose, can lead to oxidative stress. ${ }^{7,20}$

In summary, we have presented here NpFR1, a new fluorescent sensor for redox state in biological systems. NpFR1 exhibits a greater than 100-fold increase in fluorescence upon oxidation, and oxidation-reduction events are highly reversible. NpFR1 is not selective for any individual oxidising or reducing species, but rather the ratio of oxidised to reduced NpFR1 reflects the redox status of its environment. We have been able to demonstrate the utility of NpFR1 in the observation of glucose-induced oxidative stress in cultured adipocytes. This probe is a valuable contribution to the limited number of reversible probes for redox state. We have been able to ensure that we are operating at biologically-relevant reduction potentials by utilising a biologically-relevant sensing group. We continue to explore the utility of NpFR1 in various biological systems, and we are developing improved versions for the study of intracellular oxidation events.

This work was supported by a Discovery Early Career Researcher Award from the Australian Research Council and 
an Establishment Grant from the Ramaciotti Foundation. The authors acknowledge Eliot Salmon for contribution to synthetic procedures, and the facilities and the scientific and technical assistance of the Australian Microscopy \& Microanalysis Research Facility at the Australian Centre for Microscopy \& Microanalysis at the University of Sydney.

\section{References}

1 J. W. Baynes, Diabetes, 1991, 40, 405-412.

2 M. Valko, D. Leibfritz, J. Moncol, M. T. Cronin, M. Mazur and J. Telser, Int. J. Biochem. Cell Biol., 2007, 39, 44-84.

3 N. S. Dhalla, R. M. Temsah and T. Netticadan, J. Hypertens., 2000, 18, 655-673.

4 M. M. Maurice, H. Nakamura, E. A. van der Voort, A. I. van Vliet, F. J. Staal, P. P. Tak, F. C. Breedveld and C. L. Verweij, J. Immunol., 1997, 158, 1458-1465.

5 W. R. Markesbery, Free Radical Biol. Med., 1997, 23, 134-147.

6 N. Houstis, E. D. Rosen and E. S. Lander, Nature, 2006, 440, 944-948.

7 S. Furukawa, T. Fujita, M. Shimabukuro, M. Iwaki, Y. Yamada, Y. Nakajima, O. Nakayama, M. Makishima, M. Matsuda and I. Shimomura, J. Clin. Invest., 2004, 114, 1752-1761.
8 J. F. Keaney, Jr., M. G. Larson, R. S. Vasan, P. W. Wilson, I. Lipinska, D. Corey, J. M. Massaro, P. Sutherland, J. A. Vita and E. J. Benjamin, Atheroscler., Thromb., Vasc. Biol., 2003, 23, 434-439.

9 T. Yano, M. Oku, N. Akeyama, A. Itoyama, H. Yurimoto, S. Kuge, Y. Fujiki and Y. Sakai, Mol. Cell. Biol., 2010, 30, 3758-3766.

10 Y. Yamada, Y. Tomiyama, A. Morita, M. Ikekita and S. Aoki, ChemBioChem, 2008, 9, 853-856.

11 E. W. Miller, S. X. Bian and C. J. Chang, J. Am. Chem. Soc., 2007, 129, 3458-3459.

12 R. M. Kierat, B. M. Thaler and R. Kramer, Bioorg. Med. Chem. Lett., 2010, 20, 1457-1459.

13 V. Massey, J. Biol. Chem., 1994, 269, 22459-22462.

14 A. J. W. G. Visser, S. Ghisla, V. Massey, F. Müller and C. Veeger, Eur. J. Biochem., 1979, 101, 13-21.

15 K. Koenig and H. Schneckenburger, J. Fluoresc., 1994, 4, 17-40.

16 M. S. Grodowski, B. Veyret and K. Weiss, Photochem. Photobiol., 1977, 26, 341-352.

17 R. Kuhn and K. Reinemund, Ber. Dtsch. Chem. Ges., 1934, 67, 1932-1936.

18 V. Favaudon, Eur. J. Biochem., 1977, 78, 293-307.

19 D. P. Jones, V. C. Mody Jr, J. L. Carlson, M. J. Lynn and P. Sternberg Jr, Free Radical Biol. Med., 2002, 33, 1290-1300.

20 A. Fernandez-Sanchez, E. Madrigal-Santillan, M. Bautista, J. EsquivelSoto, A. Morales-Gonzalez, C. Esquivel-Chirino, I. Durante-Montiel, G. Sanchez-Rivera, C. Valadez-Vega and J. A. Morales-Gonzalez, Int. J. Mol. Sci., 2011, 12, 3117-3132. 